\title{
NOTAS SOBRE O DIREITO DE RESISTÊNCIA NO SEGUNDO TRATADO SOBRE O GOVERNO DE JOHN LOCKE
}

\begin{abstract}
Alessandra Tsuji ${ }^{1}$
Resumo: O presente artigo busca examinar o capítulo XIX do Segundo Tratado, no qual Locke concentra seus argumentos em favor do direito de resistência. Nesse percurso, ressaltam-se alguns pontos fundamentais para a demonstração de que o exercício do poder sem autoridade, que implica na perda de confiança dos governados em relação ao governante e na própria dissolução do governo, dá início ao direito do povo de resistir. Dessa maneira, busca-se compreender como a autoridade pode retornar legalmente aos súditos para que possam, por meio de uma revolução, exercer o poder supremo para agir conforme sua vontade, restabelecer o legislativo anterior ou até mesmo instituir um novo.

Palavras-chave: consentimento - autoridade - dissolução do governo - resistência - revolução.
\end{abstract}

\section{A dissolução da sociedade política}

No início do capítulo XIX, Locke aponta a necessidade de se estabelecer uma distinção entre dissolução do governo e dissolução da sociedade política. Esta, que acontece de "maneira mais comum, quase única" pela "invasão de uma força estrangeira que empreende uma conquista", implica na imediata dissolução do governo, embora a dissolução do governo não implique na dissolução da sociedade política. Uma vez que o poder de elaborar leis e, a partir delas, de julgar e punir as violações é colocado nas mãos de representantes por ocasião do pacto que forma a sociedade política para, em seguida, instituir o governo, se a sociedade política é dissolvida, os homens retornam ao estado de natureza e retomam seus poderes individuais (como a liberdade natural a qual renunciaram). Porém, o mesmo não acontece no caso da mera dissolução do governo, condição em que ainda se preserva a integridade do corpo político e, com isso, também preserva certa noção de coletividade ${ }^{3}$ presente na sociedade política. Dissolver esta

\footnotetext{
${ }^{1}$ Mestranda do Programa de Pós-Graduação em Filosofia da Universidade de São Paulo (USP) e bolsista da Capes. e-mail: alessandratsuii@gmail.com.

${ }^{2}$ LOCKE, J. Segundo tratado sobre o governo. \$211.

${ }^{3}$ Corbett destaca a dificuldade em se compreender os motivos pelos quais, após a dissolução do governo, a sociedade não se estabeleceria num quadro de anarquia; e aponta, no texto de Locke, passagens que podem levar o leitor a essa interpretação. Contudo, o comentador ressalta que sendo o governo criatura da sociedade, não pode sobreviver à morte de seu criador: "a existência de um juiz comum não pode sobreviver à ausência de um consentimento expresso para criar aquele juiz". Ocorre que, durante um período pós dissolução do governo, os homens mantêm os hábitos de ação vivenciados na sociedade política (hábitos racionais). A
} 
sociedade significa - distintamente da dissolução do governo - a desintegração total do corpo e do sentido de coletividade:

Pois, neste caso (por não ser capaz de manter-se e sustentar-se como um corpo único, integral e independente), a união pertencente a esse corpo e em que este consistia deve necessariamente cessar e, portanto, todos retornam ao estado em que se encontravam antes, com liberdade de agir por si mesmos e prover a própria segurança, como julgarem mais adequado em alguma outra sociedade. ${ }^{4}$

Para compreender o motivo pelo qual a conquista estrangeira é a via "quase" exclusiva da dissolução da sociedade política é preciso observar a noção de consentimento, conforme aparece no texto de Locke. Nesse percurso, é importante ter em vista que a formação da sociedade política pelo consentimento fora muito criticada por aqueles como Robert Filmer, por exemplo - que viam nessa noção a ameaça da anarquia, uma vez que lhes parecia inevitável que tendo o indivíduo dado o consentimento, também poderia retirá-lo a qualquer momento. Recordemo-nos, contudo, a partir da interpretação de John Marshall, que no Segundo Tratado:

Locke respondeu a Filmer que não havia possibilidade de dissolução da sociedade política por parte de qualquer geração particular por uma simples retirada do consentimento, pois uma vez que um membro tivesse se unido a uma sociedade política, ele teria que permanecer nessa sociedade de maneira inalterável, enquanto ela subsistisse. ${ }^{5}$

Além disso, o consentimento aparece no texto de Locke profundamente relacionado com a propriedade, já que ao consentir na obediência às leis da sociedade, os membros que a erigiram devem consentir obrigatoriamente na regulação de suas propriedades, já que estas estão sob a proteção do governo civil:

Pois seria uma franca contradição qualquer pessoa entrar em uma sociedade com outras para a segurança e a regulamentação da propriedade e, não obstante, supor que sua terra, cuja propriedade

permanência do agir conforme o hábito é curta, pois assim que os homens se dão conta de que não são mais recompensados, os hábitos são enfraquecidos. Por isso a necessidade de se estabelecer um novo governo, um novo juiz sobre a terra, logo após a dissolução do anterior. Cf.: CORBETT. The Lockean Commonwhealth. p. 104-105.

${ }^{4}$ LOCKE, J. Segundo tratado sobre o governo. \$211.

5 MARSHALL, John. John Locke: Resistence, Religion and Responsibility. Cambridge University Press. p. 208. 
deverá ser regulamentada pelas leis dessa sociedade deva estar isenta da jurisdição do governo do qual o proprietário da terra é súdito (...). Portanto, quem quer que, desse momento em diante, por herança, compra, permissão ou outras vias, usufrua de qualquer parte da terra, assim anexada a tal sociedade política e sob o seu governo, deve recebêla com as condições às quais está submetida; isto é, submetê-la ao governo da sociedade sob cuja jurisdição ela se encontra, tanto quanto qualquer súdito desta. ${ }^{6}$

O respeito às leis positivas na sociedade política assim como à lei natural no estado de natureza são meios para impedir a instauração do estado de guerra. Por isso, ao analisar as condições para a resistência legítima no Segundo Tratado, John Dunn argumenta que se deve tomar o direito de resistência como derivado do estado de guerra. Isso porque as ações humanas particulares que iniciam esse estado são praticadas tanto no estado de natureza quanto na sociedade política, e a resistência seria uma espécie de resposta para a antítese dessas duas condições nas quais a lei (natural ou positiva) funciona como barreira que promove paz e segurança, em oposição ao uso da força sem direito. Daí o intérprete defender a aplicação do conceito de estado de guerra lockeano para compreender a conquista, a usurpação e a tirania, conforme são apresentadas nos capítulos XVI, XVII e XVIII, respectivamente. ${ }^{7}$

Por essa via, ao se referir à conquista estrangeira, Dunn remonta à origem da escravidão conforme assumida por Locke, ou seja, a "justa execução contra um agressor". Se cada sociedade é um corpo político em estado de natureza em relação a outros corpos políticos, há, na relação entre esses corpos, limites previstos para a execução da lei de natureza, tanto quanto são previstos nas relações entre indivíduos naquele estado. ${ }^{8}$ Por isso, uma vez que, segundo Locke, cada indivíduo encarrega-se apenas de seus próprios pecados, os homens não combatentes, as esposas e filhos não podem ser escravizados, não perdem o direito à liberdade. Deste modo, se é evidente que o conquistador injusto está impedido da aquisição de domínio e propriedade do conquistado, por outro lado, é preciso notar que ao conquistador justo cabe somente o direito de punição e reparação aos danos que lhe foram causados pelo conquistado que agiu com injustiça ao violar a lei. Disso estão excluídos títulos de propriedade, "especialmente da terra", que extrapolam a medida de reparação. Isso porque a terra "tem um valor capital como fonte de riqueza contínua que está além do dano que qualquer país poderia (...) infligir sobre outro”. E mesmo

\footnotetext{
${ }^{6}$ LOCKE, J. Segundo tratado sobre o governo. \ 120

${ }^{7}$ DUNN, J. The Political Thought of John Locke. 2000. p. 172.

${ }^{8}$ DUNN, J. The Political Thought of John Locke. 2000. p. 174-175.
} 
considerando um dano tão significativo, sendo as terras dos conquistados "em algum sentido a propriedade de suas famílias", as exigências destas teriam prioridade sobre as exigências dos conquistados. Assim, as maneiras lícitas pela qual o conquistador justo poderia ter suas perdas reparadas seriam unicamente a "apropriação da receita" das posses dos conquistados e o emprego do trabalho destes, mas não a própria terra, capaz de gerar receita para muito além da reparação devida ao conquistador. Isso, conforme ressalta Dunn, inviabiliza a legitimidade da conquista estrangeira na visão lockeana. ${ }^{9}$

A explanação de Dunn nos ajuda a compreender os motivos pelos quais, no final do capítulo XVI (Da conquista), Locke aponta como nocivo o conquistador estrangeiro que, ainda que empreenda uma guerra justa, extrapola seu direito de punição e reparação para aqueles que são inocentes por não terem empreendido a guerra contra o conquistado; e, ainda, o motivo pelo qual o filósofo considera culpado de iniciar um estado de guerra aquele conquistador que avança sobre o campo da propriedade:

De modo que [o conquistador] não pode ter em virtude da conquista, nenhum título [lícito] ao domínio sobre [os inocentes,] nem transmiti-lo a sua descendência; mas será um agressor, se atentar contra as propriedades deles, colocando-se assim em estado de guerra contra eles. $^{10}$

Mais adiante, Locke argumenta que, em casos assim, a reação é aceitável e mesmo recomendável, pois esta visaria à proteção do direito em relação ao uso da força que o extrapola:

Donde fica claro que o repúdio a um poder que a força e não o direito instalou sobre alguém, embora tenha o nome de rebelião, não constitui contudo ofensa a Deus, mas é o que Ele permite e aprova, mesmo que intervenham promessas e alianças, quando obtidas pela força. ${ }^{11}$

Locke não se detém por muito tempo no tema da dissolução da sociedade política no capítulo XIX, e praticamente limita-se, como vimos, a dizer que ela ocorre quase unicamente pela força externa, ou seja, pela invasão estrangeira no momento da conquista. E quanto à consequente dissolução do governo a partir da dissolução da sociedade, diz apenas:

\footnotetext{
${ }^{9}$ DUNN, J. The Political Thought of John Locke. 2000. p. 175-177.

${ }^{10}$ LOCKE, J. Segundo tratado sobre o governo. \196.

${ }^{11}$ LOCKE, J. Segundo tratado sobre o governo. \$196.
} 
E não são precisos muitos argumentos para provar que, quando a sociedade é dissolvida, o governo não pode continuar, sendo isso tão impossível quanto a estrutura de uma casa subsistir quando seus materiais são espalhados ou dissipados por um turbilhão, ou transformados num confuso amontoado por um terremoto. ${ }^{12}$

\section{Da dissolução do governo por questões internas}

Locke dedica-se, então, a demonstrar como a alteração do legislativo pode significar essa dissolução pela via interna, e explica que o legislativo, como poder supremo, é o componente unificador do corpo, o elemento que atribui a esse corpo a coerência e a arbitragem capaz de afastar o estado de guerra e tornar a sociedade política um estado de paz. Assim, a interrupção ou dissolução do legislativo que foi estabelecido pela maioria é a interrupção daquela vontade una que motivou a própria formação do corpo político.

Parece-nos apropriado aqui, tomar essa vontade conforme Locke menciona no capítulo XI, ou seja, vontade que se coaduna ao cumprimento da lei de natureza, a qual "persiste como uma eterna regra para todos os homens, sejam eles legisladores ou não."13

Locke argumenta que, no momento da instituição do governo, ocorre um depósito do poder legislativo nas mãos daqueles que a comunidade considerou convenientes, e esse ato dá a forma do governo. ${ }^{14}$ A alteração do legislativo implicaria, portanto, em sua dissolução, uma vez que:

(...) é no legislativo que os membros de uma sociedade política se unem e se compõem num só corpo vivo e coerente. Ele é a alma que dá forma, vida e unidade à sociedade política e de que os diversos membros extraem sua influência, simpatia e conexão mútuas. Por conseguinte, quando o legislativo é interrompido ou dissolvido, seguem-se a dissolução e a morte. ${ }^{15}$

Isso porque o legislativo expressa uma vontade unificada que, por meio do consentimento, é estabelecida como:

o primeiro e fundamental ato da sociedade, pelo qual se provê à continuação de sua união, sob a direção das pessoas e dos vínculos das

\footnotetext{
12 LOCKE, J. Segundo tratado sobre o governo. \$211.

${ }^{13}$ LOCKE, J. Segundo tratado sobre o governo. \$135.

${ }^{14}$ LOCKE, J. Segundo tratado sobre o governo. \$136.

15 LOCKE, J. Segundo tratado sobre o governo. \$212.
} 
leis elaboradas por pessoas autorizadas a tal mediante o consentimento e nomeação por parte do povo. ${ }^{16}$

Desse modo, somente as leis que se façam dessa maneira conectam e obrigam seus membros e lhes garante a proteção de suas pessoas e bens.

Não é possível dizer que há, na dissolução do governo, um movimento do povo no sentido de retirar o consentimento dado. Ocorre, sim, por parte do magistrado, uma demonstração de desvio no propósito pelo qual o governo foi instituído. Por isso, é possível assumir que além de dissolvê-lo pela força externa, o governo também é dissolvido a partir do interior.

Nesse ponto, recorremos a Ashcraft, para quem Locke preocupa-se sobretudo, ao escrever os Dois Tratados, em demonstrar que sob certas condições a resistência ao rei é legítima e que, portanto, os indivíduos não somente podem como devem engajar-se em um processo de resistência ativa. Assim, uma vez que tal ação deve ocorrer, de maneira justa, quando o rei se torna um tirano, é preciso mostrar ao povo quando e como essa transformação ocorre e, por essa via, produzir a justificativa para a ação. ${ }^{17}$

Ainda na interpretação de Ashcraft, duas e convergentes são as respostas lockeanas para a pergunta acerca do que seja a tirania. A primeira relaciona-se com uma deturpação do fim para o qual a sociedade e o governo foram estabelecidos, quando o governante substitui a lei pela sua própria vontade e esta diverge da preservação das propriedades dos súditos. Para Ashcraft há, neste caso, uma "subversão" da finalidade do governo. ${ }^{18}$ Nesse sentido, encontramos a seguinte afirmação de Locke acerca da tirania:

Consiste ela em fazer uso do poder que alguém tenha nas mãos não para o bem daqueles que estiverem submetidos a esse poder, mas para sua vantagem própria, distinta e privada; quando o governante (...) não faz da lei, mas de sua vontade, a regra, e suas ordens e ações não estão dirigidas à conservação das propriedades de seu povo, mas à satisfação de sua própria ambição, vingança, cobiça ou qualquer outra paixão irregular. ${ }^{19}$

Ashcraft aponta também a segunda definição de Locke para a tirania, segundo a qual essa se estabelece pelo uso da força que o governante possui - em decorrência da confiança que lhe fora depositada - sobre o súdito, porém sem que esteja autorizado para

\footnotetext{
${ }^{16}$ LOCKE, J. Segundo tratado sobre o governo. \$212.

${ }^{17}$ Cf.: ASHCRAFT. R. "Locke's political Philosophy". In: The Cambridge Companion to Locke. p. 227.

${ }^{18}$ Cf.: ASHCRAFT. R. "Locke's political Philosophy". In: The Cambridge Companion to Locke. p. 228.

${ }^{19}$ LOCKE, J. Segundo tratado sobre o governo. \$199
} 
empregá-la. Isso indica a existência de limites na aplicação da lei, os quais o governante não pode ultrapassar. Ou seja, nesse caso a "subversão" relaciona-se com a origem da autoridade (e não mais com a finalidade do governo), a qual, como vimos, é derivada "do consentimento do povo coletivamente constituído." ${ }^{20}$ Sobre esse aspecto da tirania, Locke argumenta:

Onde termina a lei, começa a tirania, se a lei for transgredida para prejuízo de outrem. E todo aquele que, investido de autoridade, exceda o poder que lhe é conferido por lei e faça uso da força que tem sob seu comando para impor ao súdito o que a lei não permite, deixa, com isso, de ser magistrado. ${ }^{21}$

A convergência das duas definições, de acordo com a interpretação de Ashcraft, parece se dar na noção de consentimento popular no estabelecimento da autoridade política. A partir dela é possível identificar o governante como aquele que representa a sociedade política e que, portanto, está investido do poder da lei para fazer cumprir, como vontade do povo, o que a lei expressa. ${ }^{22}$ Tanto a vontade quanto o poder não são, portanto, próprios do governante. Por isso Locke afirma:

Quando, porém, [o governante] deixa essa representação, essa vontade pública, e passa a agir segundo sua própria vontade particular, degrada-se e não é mais que uma pessoa particular sem poder e sem vontade, sem direito algum à obediência, pois que não devem os membros obediência alguma senão à vontade pública da sociedade. ${ }^{23}$

Ashcraft ressalta ainda que a lei é o limite que, uma vez ultrapassado pelo governante, resulta na perda da autoridade em favor daqueles que a detinham originalmente, ou seja, ao povo como fonte da autoridade. Tal perda implica na mudança da condição do governante, que deixa de ser pessoa pública, retornando à condição de pessoa privada que, como tal, "não tem direito de usar a força contra o povo", mas, "de fato, o povo tem o direito de defender-se, e assim resistir por meio da força às ações de um tirano." 24

\footnotetext{
${ }^{20}$ Cf.: ASHCRAFT. R. "Locke's political Philosophy”. In: The Cambridge Companion to Locke.p. 229.

${ }^{21}$ LOCKE, J. Segundo tratado sobre o governo. $\$ 202$.

${ }^{22}$ Cf.: ASHCRAFT, R. "Locke's political Philosophy". In: The Cambridge Companion to Locke. p. 229.

${ }^{23}$ LOCKE, J. Segundo tratado sobre o governo. \$151.

${ }^{24}$ Cf.: ASHCRAFT, R. "Locke's political Philosophy". In: The Cambridge Companion to Locke. p. 230.
} 
Para saber a quem responsabilizar pela alteração no legislativo, Locke afirma que é preciso conhecer a forma de governo na qual essas alterações ocorrem e toma como exemplo a monarquia da Inglaterra de seu tempo para cumprir essa tarefa. ${ }^{25}$

Considera, portanto, o poder político exercido: 1) por um monarca que chegou ao poder por sucessão hereditária; 2) por uma "assembleia de nobreza hereditária" (a Câmara dos Lordes) e 3) por "uma assembleia de representantes escolhidos pelo povo" (a Câmara dos Comuns), tendo o monarca "o poder executivo constante e supremo, e com ele o poder de convocar os outros dois em períodos determinados de tempo". ${ }^{26}$

Assumindo-se essa forma de governo, manifesta-se alteração do legislativo quando: 1) a vontade do príncipe for colocada no lugar das leis, passando a constituir um novo legislativo, porém não autorizado, não de acordo com o encargo dado em confiança; 2) “o príncipe [impedir] que o legislativo se reúna no momento devido ou que aja livremente conforme os fins para os quais foi constituído",27; 3) o príncipe fizer uso de poder arbitrário para alterar eleitores ou procedimentos eleitorais (ou seja, quem escolheria não seriam os representantes do povo, mas a escolha seria feita de acordo com o interesse do príncipe ou conforme o procedimento que mais o favorecesse); 4) o príncipe ou o legislativo permitir que um poder estrangeiro seja exercido sobre o povo, já que tal conduta seria inadequada ao fim mesmo pelo qual as pessoas abriram mão de seu poder em estado de natureza para formar o corpo político "integral, livre e independente e [governado] pelas suas próprias leis" 28

Nestes quatro procedimentos, Locke defende que ao príncipe (portanto ao executivo) deve ser atribuída a responsabilidade por essa alteração do legislativo, pois, uma vez que "a força, o tesouro e os cargos do Estado" podem ser empregados por ele, tal príncipe representa uma ameaça concreta ao povo, já que somente ele teria "nas mãos o poder de aterrorizar ou suprimir os oponentes como facciosos, revoltosos e inimigos do governo". O filósofo, contudo, está disposto a responsabilizar também o legislativo caso este colabore com o príncipe ou deixe de impedi-lo quando tenha poderes para tal. ${ }^{29}$

\footnotetext{
25 Ashcraft volta a defender que o texto de Locke é eminentemente de intervenção e essa intenção é notada quando o filósofo emprega a forma de governo da Inglaterra de seu tempo como modelo concreto para sua análise. De maneira que o povo possa não somente compreender que se deve resistir diante da tirania, mas constatar que de fato ela existe (ou existiu) naquele momento. Isso porque Locke precisaria convencer o povo a agir - ou pelo menos apoiar aqueles que pretendessem agir - contra o governo no final do século dezessete na Inglaterra. Cf.: ASHCRAFT, R. "Locke's political Philosophy”. In: The Cambridge Companion to Locke. p.231.

${ }^{26}$ LOCKE, J. Segundo tratado sobre o governo. $\$ 213$.

27 LOCKE, J. Segundo tratado sobre o governo. \$217.

${ }^{28}$ LOCKE, J. Segundo tratado sobre o governo. \$217.

${ }^{29}$ Laslett defende que até o parágrafo 218 o capítulo tenha sido escrito bem antes de 1688, pois considera o conteúdo bastante hipotético para ser tomado como comentário Whig sobre a revolução. Cf.: LOCKE, J. Segundo tratado sobre o governo. \211 (ver nota de rodapé 1).
} 
Além das quatro mencionadas, Locke distingue mais uma maneira pela qual o governo pode ser dissolvido ${ }^{30}$; qual seja, a negligência ou abandono do cargo por parte do executivo, de maneira a inviabilizar a execução das leis, tornando-as sem efeito ${ }^{31}$; e, na sequência, mais uma vez há a indicação de que devemos nos lembrar que a dissolução do governo não ocorre pela retirada do consentimento e retomada dos poderes aos quais os indivíduos renunciaram na ocasião da instituição do corpo político, mas sim pela perda da eficácia da lei como elemento que mantinha os vínculos da sociedade política. Tal perda dissolve o governo estabelecido, de maneira tal que:

Onde não mais existe a administração de justiça para a garantia dos direitos dos homens e tampouco nenhum poder restante no seio da comunidade para dirigir a força ou prover às necessidades do público, com certeza não resta governo algum. Onde as leis não podem ser executadas é como se não houvesse leis, e um governo sem leis é (...) um mistério político, inconcebível para a capacidade humana e incompatível com a sociedade humana. ${ }^{32}$

$\mathrm{Na}$ sequência, apresenta o resultado da dissolução do governo sob a perspectiva do povo, e faz a defesa do direito que este tem para resistir:

Neste caso e em outros análogos, quando o governo é dissolvido, o povo se vê livre para prover por si mesmo instituindo um novo legislativo, diferente do outro pela mudança das pessoas ou da forma, ou de ambas, conforme julgar mais adequado à sua segurança e bem. ${ }^{33}$

Uma vez que o consentimento é dado em confiança, é preciso notar que a perda desta ocorre posteriormente a uma condição na qual o governo já está dissolvido, porém na qual o povo permanece como coletividade, agora livre para resistir por meio da instituição de um novo legislativo.

Locke aponta para o direito de resistência como algo que deve estar sempre presente. Tal elemento parece se impor como medida profilática para conter, na sociedade

\footnotetext{
30 Essa maneira aparece no $\int 219$ (que segundo Laslett teria sido escrito, assim como o parágrafo seguinte, 220, após 1689.). A organização da sequência dos parágrafos está meio confusa. Locke sinaliza para uma outra maneira no \ 219 e depois um "segundo lugar, outra maneira..." no parágrafo 221, no qual também aparece, em seguida "em primeiro lugar", sem um provável segundo lugar.

${ }^{31}$ Laslett afirma que este parágrafo faz, provavelmente, referência ao afastamento do governo, por abdicação, de Jaime II. Cf.: LOCKE, J. Segundo tratado sobre o governo. \ 219 (ver nota de rodapé 1).

32 LOCKE, J. Segundo tratado sobre o governo. \$219.

${ }^{33}$ LOCKE, J. Segundo tratado sobre o governo. \$220.
} 
política, o desequilíbrio manifestado pelo comprometimento da liberdade conforme pensada para existir na sociedade política ${ }^{34}$. Por isso, Locke expressa claramente a necessidade dessa precaução:

Pois a sociedade não pode jamais, por culpa de terceiros, perder o direito natural e original de preservar-se. $O$ que só pode ser feito por um legislativo estabelecido e uma execução justa e imparcial das leis por este elaboradas. Mas o estado da humanidade não é tão miserável que não seja capaz de usar esse remédio antes que seja tarde demais para procurar outro. Dizer ao povo que pode prover por si mesmo instituindo um novo legislativo, quando (...) o antigo já não existe, é dizer-lhe que pode esperar alívio quando for tarde demais e o mal estiver além de toda cura. ${ }^{35}$

Além da dissolução do governo ocorrer pela alteração do legislativo - conforme os procedimentos aqui apresentados - Locke sustenta que a violação da propriedade privada como ação contrária ao encargo confiado ao governante é uma ação que também dissolve o governo, já que a preservação da propriedade é "a razão pela qual os homens entram em sociedade" e, além disso:

o fim para o qual elegem e autorizam um legislativo é a formulação de leis e o estabelecimento de regras como salvaguarda e defesa da propriedade de todos os membros da sociedade, para limitar o poder e moderar o domínio de cada parte ou membro desta. ${ }^{36}$

Locke volta a utilizar a noção de estado de guerra para se referir à condição iniciada por aqueles que ameaçam ou fazem de fato o uso da força sem autoridade, provocando com isso a dissolução do governo. Além disso, no mesmo capítulo ressalta como uma segunda ofensa contra o encargo confiado ao executivo - a primeira é a violação da propriedade privada - o mesmo uso da força, do tesouro e cargos, porém agora para a obtenção de apoio dos representantes, visando à realização de seus propósitos particulares, bem como a prescrição aos eleitores acerca de sua escolha, favorecendo alguém "a quem, por meio de solicitações, ameaças, promessas ou de outro modo,

34 “A liberdade do homem em sociedade consiste em não estar submetido a nenhum outro poder legislativo senão àquele estabelecido no corpo político mediante consentimento, nem sob o domínio de qualquer lei afora as que promulgar o legislativo, segundo o encargo a este confiado". Cf. LOCKE, J. Segundo tratado sobre o governo. $\$ 22$

35 LOCKE, J. Segundo tratado sobre o governo. \220.

${ }^{36}$ LOCKE, J. Segundo tratado sobre o governo. \222. 
conquistou para seus próprios desígnios". Há também, nesses casos, uma quebra de confiança que, segundo Locke, não pode mais ser restabelecida. Esse "abuso do encargo confiado", afirma Locke, ainda que seja como tentativa, desobriga o povo da obediência. ${ }^{37}$

Neste momento, é interessante uma consulta ao capítulo III do Segundo Tratado, no qual Locke define o Estado de Guerra como: "um estado de inimizade e destruição", prosseguindo:

portanto, aquele que declara por palavra ou ação, um desígnio firme e sereno, e não apaixonado ou intempestivo, contra a vida de outrem, coloca-se em estado de guerra com aquele contra quem declarou tal intenção e, assim, expõe sua própria vida ao poder dos outros, para ser tirada por aquele ou por qualquer um que adira a seu embate. Pois é razoável e justo que eu tenha o direito de destruir aquilo que me ameaça de destruição. ${ }^{38}$

Aquele que inicia o estado de guerra age de maneira calculada, premeditada, porém não apoiada na razão, mas na admissão de que detém uma espécie de privilégio (pelo uso da força) sobre o outro. Tal ação permite, segundo Locke, uma reação para restabelecer uma medida que foi alterada.

É importante lembrar que Locke compara o homem que inicia o estado de guerra a um animal inferior (como um lobo ou um leão) e, nesse contexto, John Dunn nos ajuda na interpretação do texto de Locke, ao explicar que "a razão pela qual os homens são iguais é a posição que eles compartilham em uma ordem normativa, a ordem da criação" e, ainda, "se eles infringem as normas daquela ordem, eles perdem seu estatuto normativo de igualdade" ${ }^{39}$. Isso acontece porque a infração da norma resulta no confisco da sua posição (perda de direito, por uma parte e ganho de um direito pela parte que reage para restabelecer o equilíbrio na relação de igualdade perante a lei de natureza). A dissolução do governo expressa situação similar, porém, na sociedade política. Dessa maneira, quando ocorre o uso ou ameaça de uso da força sem autoridade e consequente perda da confiança, o povo tem o direito de resistir porque a norma (lei) foi infringida.

\footnotetext{
${ }^{37}$ LOCKE, J. Segundo tratado sobre o governo. \ 222.

${ }^{38}$ LOCKE, J. Segundo tratado sobre o governo. \$16.

${ }^{39}$ Cf.: DUNN, J. The Political Thought of John Locke. 2000. p. 106 - 107.
} 


\section{Resistência, revolução e rebelião}

Neste ponto, parece pertinente acompanhar o argumento de Corbett, que propõe uma distinção entre resistência e revolução ${ }^{40}$ para facilitar o trabalho interpretativo. Nesse sentido, o comentador afirma que embora relacione tanto resistência quanto revolução ao poder executivo que cada indivíduo possui em estado de natureza, existe o problema de transpor para o povo um direito que é fundamentalmente individual, de modo que é possível analisar a questão com mais clareza quando colocamos, de um lado, o direito de resistência - natural, possuído pelo indivíduo e empregado na autopreservação - e, de outro, o direito popular de revolução - este artificial, que caberia ao povo, podendo ser reivindicado (unicamente) após a dissolução do governo. ${ }^{41}$

Se para Locke, conforme a explanação de Corbett, o direito de revolução deve estar sempre no horizonte do povo como único elemento capaz de "assegurar que os governantes não violem desnecessariamente a constituição e o governo da lei, ou as transgridam para subverter o bem público sob o disfarce de servi-lo", é preciso instruir o povo para que não se torne "paranoico" a ponto de produzir guerras civis sem necessidade, o que seria tão grave quanto a conquista estrangeira. ${ }^{42}$

Nesse sentido, se é necessário que o direito individual de resistência seja mantido e exercido em sociedade - quando não há tempo para recorrer a um juiz na terra ou quando ocorre alguma falha nesse procedimento - também deve permanecer para sustentar revoluções na sociedade civil.

Isso porque dificilmente os indivíduos se sensibilizam com aquele que sofreu a agressão e, portanto, tal indivíduo precisa ter o direito de recorrer ao uso da força de acordo com sua própria consciência, como autodefesa. Contudo, conforme Corbett ressalta, Locke estabelece um padrão para a reação do homem quando possuidor do poder para resistir: "Razão é o padrão pelo qual ele, senão o Céu, julga a resistência" e isso não pode ser alterado na sociedade política. Nela, o estado de guerra existe, como vimos, "sempre que a lei é incapaz de compensar pela perda da vida". Além disso, argumenta

\footnotetext{
40 Importante ressaltar que o termo revolução aparece somente duas vezes no Segundo Tratado - no plural, revoluções (revolutions). É empregado nos parágrafos 223 e 225 em conformidade com um regime de historicidade que aponta para o passado, no sentido próximo à noção de História como Magistrae Vitae. Tal ponto de vista, predominante até meados do século XVIII, concordava com a noção de revolução empregada na astronomia para designar o movimento cíclico dos astros. Por isso, o significado de se fazer uma revolução aqui estaria mais próximo de "designar um movimento de retorno a algum ponto preestabelecido e, por extensão, de volta a uma ordem predeterminada." (Cf. SILVA, R. O. da. "Revolução, História e tempo". In: História: debates e tendências. 2015. p. 255.

${ }^{41}$ Cf.: CORBETT, Ross J. The Lockean Commonwealth. p. 95.

${ }^{42}$ Cf.: CORBETT, Ross J. The Lockean Commonwealth. p. 95
} 
Corbett, "o direito de fazer guerra (...) não é um sinal de poder político e, assim, não deve necessitar do consentimento de outros para ser um direito."

O que o ingresso na sociedade política permite é uma restrição ao direito de resistência que, por isso mesmo, não poderia "ser reclamado sem desafiar a autoridade" ${ }^{44}$.

O direito de revolução, se observado a partir do direito individual, seria um direito compartilhado no estado de natureza que pode existir ainda em meio coletivo, posteriormente à dissolução do governo. Por isso Corbett defende que indivíduos que se vejam oprimidos poderão resistir à força que lhes foi imputada apesar da baixa probabilidade (ou mesmo nenhuma) de sucesso caso a resistência não se dê pela maioria, pois a ausência de "esperança sem a maioria significa que esse é um direito raramente exercido, mas isso não o faz menos que um direito." 45

A revolução manteria, portanto, um parentesco com o poder federativo, na interpretação de Corbett, por isso ele diz que seria uma espécie de "apelo ao Céu exercido para prevenir a tirania e para dar ao povo a oportunidade de restabelecer seu legislativo". Assim, é preciso que a maioria esteja engajada de alguma forma (seja na participação ativa ou como apoiadora), de outro modo, a revolução não seria apreciada como ato do povo; e o julgamento da maioria (talvez como consciência do corpo político) é fundamental para que uma revolução seja "correta". Nas palavras do intérprete, "o julgamento do indivíduo quanto à possibilidade de tomar parte em uma revolução deve (...) mirar não somente para o que a razão diz que é justo," o que Locke se esforça para mostrar ao tratar da dissolução do governo, "mas também para o que a maioria decidirá."

Jean-Fabien Spitz ressalta, no trabalho de Locke, uma inovação extremamente relevante para a história do pensamento político quando trata do problema da transposição do direito individual de resistência para o povo. Isso porque Locke teria recusado a ideia de soberania do povo como instituição, elaborando uma teoria da supremacia do povo que preserva os direitos do indivíduo. Além disso, teria recusado a soberania do Parlamento (que poderia impedir que, de um modo ou de outro, o povo possuísse o direito de resistir). Da mesma forma, Locke teria rechaçado qualquer interposição da questão acerca da opressão e da resistência entre a assembleia representativa e aqueles que detêm o poder executivo. O intérprete afirma que a intenção consciente de Locke foi a de colocar essa questão entre um povo desprovido de todas as leis e a instância que faz as leis e que as executa. ${ }^{47}$ Assim,

${ }^{43}$ Cf.: CORBETT, Ross J. The Lockean Commonwealth. p. 98-99.

${ }^{44}$ CORBETT, Ross J. The Lockean Commonwealth. p. 99

45 Segundo Corbett, é preciso destacar o esforço de Locke em apontar os casos em que não se deve tolerar atos ditos de resistência que, contudo, são inaceitáveis, como: agitar o povo para a revolução sem motivo e resistir quando há possibilidade de apelo à lei. Cf.: CORBETT, Ross J. p. 99.

${ }^{46}$ CORBETT, Ross J. The Lockean Commonwealth. p. 100.

${ }^{47}$ Spitz, Jean-Fabien. John Locke et les fondements de la liberté moderne. 2001. p. 290-298. 
A inovação de Locke não consiste em recusar toda soberania do rei, mas em recusar a própria soberania como conceito político que permitiria definir a natureza do poder do povo sobre ele mesmo. Ele a rejeita ao mesmo tempo nas mãos do rei, do Parlamento, mas também entre as do povo como entidade legal incorporada, e ele somente a reconhece no povo constituinte, ou no conjunto discreto que formam as razões individuais convidadas a interpretar, por elas mesmas (e de maneira imprescritível) o que exige a lei de Deus e da natureza. ${ }^{48}$

Desvencilhar-se da armadilha presente no conceito de soberania é, para Spitz, a grande contribuição de Locke para o pensamento Constitucional. Isso porque o povo, restringindo-se a uma coleção de indivíduos, é, contudo, uma instância moral "composta de razões individuais que julgam o que é justo ou injusto" e que esse direito de julgar jamais pode ser delegado a outrem. Não pode haver sacrifício moral e da responsabilidade individual para que sociedade seja formada, pois isso seria contraditório com o fato de que tal formação só pode ser justificada se ela viabilizar que o indivíduo se realize como ser moral. Uma vez que a razão é a única com habilidade para julgar, ela deve permanecer sempre distinta da vontade, ainda que da vontade da maioria. Nesse sentido, não há possibilidade de que o povo esteja acima do governo. Se este cumpre a sua finalidade, não pode existir superior a ele. Mas é preciso lembrar que o governo é apenas um meio para a realização da lei de natureza, e que é o indivíduo quem detém o poder de determinar se a lei é violada, poder que não pode ceder a outrem, mesmo que seja a uma maioria. Por isso Spitz afirma que a tese de Locke é:

quando um indivíduo julga que o governo traiu sua missão, ele pode apelar à razão dos seus concidadãos. Seu apelo só tem chance de ser ouvido se um número suficiente desses concordarem com ele em julgar que o governo ultrapassou os limites atribuídos a ele pela sua definição funcional e pela lei de natureza. ${ }^{49}$

Em resposta à acusação de que o povo é inconstante e, possuindo tal direito de resistir, nenhum governo poderia ter permanência, Locke defende que o povo apega-se às formas e costumes e têm muita dificuldade para abandoná-la. Recorre mesmo à história da Inglaterra para afirmar que essa dificuldade para desapegar-se dos costumes "nos tem mantido, ao longo das muitas revoluções a que este reino assistiu nesta época e em outras,

48 SPITZ, Jean-Fabien. John Locke et les fondements de la liberté moderne. 2001. p. 301-302.

${ }^{49}$ SPITZ, Jean-Fabien. John Locke et les fondements de la liberté moderne. 2001. p. 301-302. 
ou nos tem trazido de volta, após algum intervalo de tentativas infrutíferas, ao nosso velho legislativo composto pelo rei, os lordes e os comuns" ${ }^{30}$. Contudo, ao se ver em condição miserável "e se encontra[r] exposto ao poder arbitrário", não importa quem esteja a frente do governo, o povo fará a revolução inevitavelmente, ainda que os governantes sejam “exaltados (...) como filhos de Júpiter, (...) sagrados ou divinos, descendentes do céu ou por este autorizados" muito tempo e "na mesma direção" para que o povo apresente reação ${ }^{52}$.

Locke aponta, contudo, para a distinção entre resistência e rebelião, bastante importante no momento de se responsabilizar o verdadeiro causador da dissolução do governo. Segundo ele, a dissolução do governo, conforme tratado neste artigo, expressaria a disposição para rebelião por parte daqueles que receberam a confiança do povo, pois entende-se que suas ações revelam oposição à autoridade pela força e, portanto, são ações próprias de rebeldes que contrariam a lei e a própria finalidade da sociedade política:

(...) quando os homens, ao entrarem em sociedade e no governo civil, excluíram a força e introduziram as leis para a conservação da propriedade, da paz e da unidade entre eles, aqueles que estabeleceram a força em oposição às leis são os que (...) promovem novamente o estado de guerra e são propriamente rebeldes. ${ }^{53}$

O mesmo se pode dizer do súdito quando emprega a força sem direito - que ele é rebelde e desencadeia um estado de guerra. Rebelião é o próprio uso da força sem direito. Uma vez que a confiança é perdida e a autoridade confiscada, a resistência se impõe como modo mais eficaz de conter os rebeldes que iniciam o estado de guerra. Isso pode ser visto na seguinte passagem, em que Locke aponta quem, com maior probabilidade, inicia a rebelião e também como remediá-la:

Os que mais provavelmente podem [rebelar-se] são aqueles que estão no poder (por sua pretensão à autoridade, pela tentação de força que detêm e pela lisonja daqueles que os rodeiam) e a maneira mais apropriada de evitar o mal é mostrar o seu perigo e a sua injustiça àqueles que estão sob a maior tentação de nele incorrer. ${ }^{54}$

\footnotetext{
${ }^{50}$ LOCKE, J. Segundo tratado sobre o governo. \$223.

${ }^{51}$ LOCKE, J. Segundo tratado sobre o governo. \$224.

52 Cf.: LOCKE, J. Segundo tratado sobre o governo. \ 225.

${ }^{53}$ LOCKE, J. Segundo tratado sobre o governo. \226.

${ }^{54}$ LOCKE, J. Segundo tratado sobre o governo. \$226.
} 
Deixar de resistir em nome da manutenção da paz seria, para Locke, ter uma paz "mantida apenas para o benefício de ladrões e opressores" príncipe ou o legislativo", acusado de trair o encargo que lhe foi confiado, é preciso atentar para a possibilidade de que o príncipe esteja apenas fazendo uso da prerrogativa. Porém, no caso de haver ocorrido violação da confiança, Locke responde que ao povo caberá esse julgamento:

Pois quem mais poderá julgar se tal depositário ou deputado age segundo o encargo a ele confiado senão aquele que o designou e que deve, por esse motivo, conservar o poder de afastá-lo quando falharem em seus cargos? ${ }^{56}$

Se, conforme Tully, a originalidade ${ }^{57}$ de Locke consiste em assentar as "formas institucionalizadas de governo" na liberdade - como elemento que o povo tem "para exercer o poder político por ele mesmo" antes da instituição do governo ${ }^{58}$-, então podemos entender que o direito de resistência não servirá apenas para a correção da perda da liberdade, mas também para prevenir que ela seja atingida. A permanência da liberdade de julgar, em poder "dos membros da sociedade política", é fundamental para que estes estejam "sempre prontos e habilitados para governar seus governantes se eles abusam do poder a eles confiado", uma vez que sob quaisquer formas de governo, prossegue Tully, "aqueles no poder serão tentados de várias maneiras a abusar do poder confiado a eles: para desenvolver um interesse separado" e contrário "ao bem do povo". 59

Diante do exposto, parece-nos correto afirmar que o direito de resistência no Segundo Tratado aparece fundamentado sobretudo na noção de que o governo é instituído a partir do consentimento e da atribuição do poder legislativo em confiança aos representantes do povo, conforme determinação da maioria. O governo, dessa forma constituído, tem por finalidade a manutenção da paz e segurança que exclui o estado de guerra e a preservação da propriedade dos súditos entendida como vida, liberdade e bens. Uma vez que as ações dos governantes violem essa confiança, o governo é dissolvido e

\footnotetext{
55 LOCKE, J. Segundo tratado sobre o governo. \$228.

${ }^{56}$ LOCKE, J. Segundo tratado sobre o governo. $\$ 240$.

57 Tully argumenta que, ao colocar o poder político originalmente nas mãos dos indivíduos de maneira que possa retornar a ele após a perda da confiança, resulta em superioridade dos meios propostos por Locke em relação às outras formas de governo que também procuram estabelecer controle sobre os abusos dos governantes, pois seria o único caminho efetivamente em acordo com a lei. Além disso, essa visão possibilita que o ato de resistir seja propriamente político, distintamente de uma condição na qual o poder político nunca tivesse pertencido, como origem, ao povo e consequentemente não pudesse voltar para as mãos desse. Cf.: TULLY, J. An Approach to Political Philosophy: Locke in Contexts. p. 318-320.

58 TULLY, J. An Approach to Political Philosophy: Locke in Contexts. p. 315.

59 TULLY, J. An Approach to Political Philosophy: Locke in Contexts. p. 317-318.
} 
revela-se, por essa violação, uma intenção própria de quem inicia o estado de guerra daquele que é rebelde -, desobrigando o súdito da obediência, de maneira que seja estabelecido o direito de resistência que, no corpo político, exprime-se como direito de revolução. Este, pertencente ao povo originalmente, representa a prevenção de abusos cometidos pelo governante e remédio para a dissolução do governo, cuja prescrição dependerá sempre do julgamento da maioria.

\section{NOTES ON THE RIGHT OF RESISTANCE IN LOCKE'S SECOND TREATISE OF GOVERNMENT}

Abstract: Present article attempts to examine chapter XIX of the Second Treatise of Government, in which Locke concentrates his arguments in favor of the Right of Resistance. In this way, we highlight some fundamental points for demonstrating that the emergence of this Right comes from the exercise of Power without authority by ruler, a condition that implies the dissolution of government - with consequent loss of confidence on the part of the governed - so that such authority returns to subjects and they can, by means of a revolution, retain the supreme power to act according to their will or to reinstate the previous legislature, or even to institute a new one.

Keywords: resistance - consent - authority - revolution.

\section{Referências Bibliográficas}

ASHCRAFT, Richard. "Locke's political Philosophy”. In: The Cambridge Companion to Locke. Cambridge: Cambridge University Press, 1995.

CORBETT, Ross J. The Lockean Commonwealth. Albany: State University of New York Press. 2009.

DUNN, John. The Political Thought of John Locke. Cambridge: Cambridge University Press, 1995.

LOCKE, J. Segundo tratado sobre o governo. In: Dois tratados sobre o governo. Trad. Julio Fischer. São Paulo. Martins Fontes. 2005.

MARSHALL, John. John Locke: Resistance, Religion and Responsibility. Cambridge: University Press, 1990.

SILVA, R. O. da. "Revolução, História e Tempo". In: História: debates e tendências. 2015.

SPITZ, Jean-Fabien. John Locke et les fondements de la liberté moderne. Paris. Presses Universitaires de France, 2001. 
TUlLY, J. An Approach to Political Philosophy: Locke in Contexts. Cambridge: Cambridge University Press. 2003. 